\title{
Material Models and their Capability for Process and Material Properties Design in Different Forming Processes
}

\author{
Konstantin Schacht ${ }^{1, a^{*}}$, Ulrich Prahl ${ }^{1, b}$ and Wolfgang Bleck ${ }^{1, c}$ \\ ${ }^{1}$ Steel Institute, RWTH Aachen University, Germany \\ akonstantin.schacht@iehk.rwth-aachen.de, bulrich.prahl@iehk.rwth-aachen.de, \\ cwolfgang.bleck@iehk.rwth-aachen.de
}

Keywords: hot forming, process modelling, properties modelling, predictive modelling.

\begin{abstract}
Hot forming of metals is important to achieve the desired shape and properties of products. The change in process behavior and final properties of materials during processing is essential for the design of new processes and products. Finite-element-software (FE-software) is nowadays widely used in industry to design and optimize hot forming processes. These FE codes need a proper description of the material behavior being developed for specific processes.

In this paper the capability of a recently developed one-point-model will be discussed to predict material behavior for the carbon steel (C-steel) family. In detail, the following topics will be discussed: (i) description of the material behavior in varying processes, (ii) definition of material properties depending on alloying content, (iii) capability to describe whole alloy families, (iv) adjusting the model parameters by a small number of experiments.
\end{abstract}

\section{Introduction}

During processing of steels several physical processes take place like grain growth, solution and precipitation of second phases, homogenization, dynamic and static softening and transformation of austenite. These processes are influenced by the overall composition and processing parameters. Usually, their effect on flow stress and other physical processes cannot be separated clearly as they are active at the same time. This makes the description of material behavior complex and different models for the simulation of material behavior were developed in the last century.

Most frequently used models are constitutive models which can be distinguished in empiricalphenomenological [1,2] and physically based description [3,4]. Typically, the first kinds of models are used to describe the material behavior in FE-software. As an example, in [5] an one-parameter dislocation density model was exemplarily developed, while in [4,6] three types of distinct dislocation densities were accounted for.

These investigations show the trend to describe more complex mechanisms reflecting the aim to give the models a higher predictive capability. However it is clear that the ability to plan a draft schedule for a specific process the models need to take into account the alloying dependence of the physical properties like strength, shear modulus, diffusivity etc. as well as their dependence on process parameters. A precise description of physical properties depending on composition being essential for all material modelling is still not available today. The ability for numerical based process optimization or the design of new steels is restricted due to the lack of this information. Even so-called physical based models typically do not account for the effect of composition on strength, shear modulus and diffusion, influencing grain growth and steady state stress.

Notably, these models do not take into account the effect of carbon on physical properties explicitly and in that they are neglecting the most influencing alloying element in steels. In several alloy families the major difference between the alloying concepts is the amount of carbon, this holds also for Precipitation-Hardened-Ferritic-Pearlitic- (PH-FP-) as for general C-steels. Taking the effect of carbon into account should therefore give the models a higher predictive capability. 


\section{Model Setup}

\begin{tabular}{|ll|}
\hline \multicolumn{2}{|l|}{ Nomenclature } \\
$T$ & Temperature \\
$T_{M}$ & Melting temperature (average between liquidus and solidus temperature) \\
$T_{S o l}$ & Solidus temperature \\
$D_{\text {Self }}$ & Self-diffusivity \\
$D_{G B}$ & Grain boundary diffusivity \\
$G$ & Shear modulus \\
$f_{e q}$ & Equilibrium ferrite fraction \\
$p_{e q}$ & Equilibrium perlite fraction \\
$T_{\gamma \rightarrow \alpha}$ & Transformation start temperature form austenite to ferrite \\
$A r_{3}$ & Ferrite start temperature without undercooling \\
$A r_{1}$ & Perlite start temperature without undercooling \\
$v_{r}$ & Cooling rate \\
$Y S$ & Yield strength \\
$T S$ & Tensile strength \\
$f_{\alpha}$ & Ferrite fraction \\
$d$ & Austenite grain size before transformation \\
$s$ & Perlite lamellar spacing \\
\hline
\end{tabular}

The model used in this work is basically represented in the final report of the project AiF 17246 $\mathrm{N} / 1$ were it was developed to describe the hot forming process of PH-FP-steels. In this paper only the main concept for the C-steel family is described in a brief manner. For a more detailed description of the model the reader is revered to [7,8]. The model accounts for grain growth, static and dynamic recrystallization, transformation and the final properties at the end of the process cycle. Flow stress as well as the strength during intermediary time are described by using a single average dislocation density. Dynamic recrystallization is induced at a critical dislocation density. During dynamic recrystallization an average dislocation density is calculated by a law of mixture, accounting for the dislocations in the deformed region and the dislocations in the dynamic recrystallized grains. Static recrystallization starts in the shipping time if not the critical dislocation density for dynamic recrystallization is reached. During static recrystallization the stored energy is decreased and the average dislocation density is again calculated by a law of mixture. For the carbon alloy family the self, grain boundary diffusivity and shear modulus are calculated depending on the melting as well as on the solidus temperature decrease by carbon content. The decrease in melting and solidus temperature depending on carbon content was calculated by ThermoCalc with database TCFE7.

For the calculation of the melting and solidus temperature $T_{M}$ and $T_{S o l}$ the average carbon composition for different C-steels (C22, C35, C45, C60) according to standard DIN EN 10083-2 were taken $[9,10]$. After linearization the according parameter were implemented into the model as a function of carbon content in weight percent $(\% \mathrm{C})$. For simplicity only a linear dependency was chosen:

$$
T_{M}=1810-129 \cdot \% C \text { and } T_{S o l}=1798-179 \cdot \% C \text {. }
$$

With the information of alloying dependent melting temperature which is manly influenced by carbon content the alloying dependent diffusivity was calculated after Lesuer et al. for self and grain boundary diffusivity [11]. 


$$
D_{\text {Self }}=6.89 \cdot 10^{-6} \cdot \exp \left(-17 \frac{T_{M}}{T}\right) \text { and } D_{G B}=10^{-4} \cdot \exp \left(-11 \frac{T_{M}}{T}\right)
$$

Following the idea of Frost and Ashby the shear modulus $G$ was calculated according to Eq. 3 .

$$
G=G_{\mathrm{o}}\left[1-0.91\left(\frac{T-300}{T_{\text {Sol }}}\right)\right] \text {. }
$$

Carbon depending steady state grain size prediction was adjusted to the results of Sakai et al. [12] assuming that within technical relevant times the grain size is limited depending on carbon content and temperature. The transformation is also calculated by using the equilibrium ferrite fraction out of ThermoCalc.

Again the equilibrium content of ferrite was calculated using the average carbon content out of the standard. As before a fitting was performed yielding the equilibrium ferrite fraction $f_{e q}$ depending on temperature and carbon content.

$$
f_{e q}=5.54357-0.0062 \cdot T-1.53075 \cdot \% C \text {. }
$$

Since Eq. 4 can also predict negative and values higher than the equilibrium ferrite content the formulation in Eq. 4 is only valid for positive values and values which are smaller than 1 subtracted by the equilibrium perlite fraction $p_{e q}$, Eq. 5 .

$$
p_{e q}=(\% C-0.02) /(0.8-0.02)
$$

Ferrite starts to grow depending on the cooling rate. The growth rate of ferrite is calculated by a rate equation with the equilibrium ferrite content as a driving force. Ferrite growth stops once the perlite start temperature is reached. Perlite transformation start temperature is assumed to have the same dependence on the degree of undercooling as the ferrite transformation start temperature. Instead of $\mathrm{Ar}_{3}$ in Eq. 6, $\mathrm{Ar}_{1}$ was chosen. $\mathrm{Ar}_{3}$ and $\mathrm{Ar}_{1}$ depend on carbon $(\% \mathrm{C})$, manganese $(\% \mathrm{Mn})$ and silicon $(\% \mathrm{Si})$ content in weight percent.

$$
\begin{aligned}
& T s_{\gamma \rightarrow \alpha}=A r_{3}-19 \cdot v_{r}^{0.481}-0.5 \cdot \exp \left(\frac{0.042 \cdot d+7.8}{(2.11)^{1.35}}\right) . \\
& A r_{3}=911-255 \cdot \% C-7 \cdot \% M n+19 \cdot \% S i, A r_{1}=739-22 \cdot \% C-7 \cdot \% M n+2 \cdot \% S i .
\end{aligned}
$$

For the prediction of yield strength (YS) and tensile strength (TS) empirical equation from Gladman are adopted [13].

$$
\begin{aligned}
& Y S=f_{\alpha}^{1 / 3}\left[35+58 \cdot \% M n+17(d / 3)^{-1 / 2}\right]+\left(1-f_{\alpha}^{1 / 3}\right)\left[198+3 \cdot s^{-1 / 2}\right]+63 \cdot \% S i . \\
& T S=f_{\alpha}^{1 / 3}\left[246+18(d / 2)^{-1 / 2}\right]+\left(1-f_{\alpha}^{1 / 3}\right)\left[719+2 \cdot s^{-1 / 2}\right]+97 \cdot \% S i
\end{aligned}
$$

Pearlite lamellar spacing in $\mu \mathrm{m}$ was assumed to depend inversely on the degree of undercooling. Undercooling was calculated according to [14], whereas the final ferrite grain size was assumed to depend on the initial austenite grain size (AGS) linearly. The transformation model was adjusted to predict plausible phase fractions and modelling of final properties was adjusted to match the in the standard specified values for different product dimensions. 


$$
s=10 /\left[19 \cdot v_{r}^{0.481}-0.5 \cdot \exp \left(\frac{0.042 \cdot d+7.8}{(2.11)^{1.35}}\right)\right]
$$

\section{Experimental Details}

For the validation and adjustment of the model two plain carbon steels used for forged parts as well as for flat products were chosen, namely $\mathrm{C} 15$ and $\mathrm{C} 60$. Composition of the material delivered by Georgsmarienhütte $\mathrm{GmbH}$ is given in Table 1.

Table 1: Chemical composition in wt-\% of C15 and C60 as delivered by GMH.

\begin{tabular}{|c|c|c|c|c|c|}
\hline Alloy & $\mathrm{C}$ & $\mathrm{Si}$ & $\mathrm{Mn}$ & $\mathrm{Cr}$ & $\mathrm{Ni}$ \\
\hline $\mathrm{C} 15$ & 0.16 & 0.16 & 0.57 & 0.11 & 0.07 \\
\hline C60 & 0.62 & 0.19 & 0.88 & 0.08 & 0.09 \\
\hline
\end{tabular}

Hot compression tests where perform on deformation dilatometer DIL 805A/D. Cylindrical specimens without lubrication pockets and a diameter of $5 \mathrm{~mm}$ and $9 \mathrm{~mm}$ length were used. Tests were performed to investigate flow stress and recrystallization behavior depending on process cycle.

\section{Model Results}

The flow stress description of the one-point-model by a single dislocation density was adjusted to the $\mathrm{C}$ steel family, by the fitting of the flow stress prediction to the experimental flow curves from $\mathrm{C} 15$ and $\mathrm{C} 60$ by one set of parameters. Comparison of the experimental and simulated flow stress is given in Fig. 1.

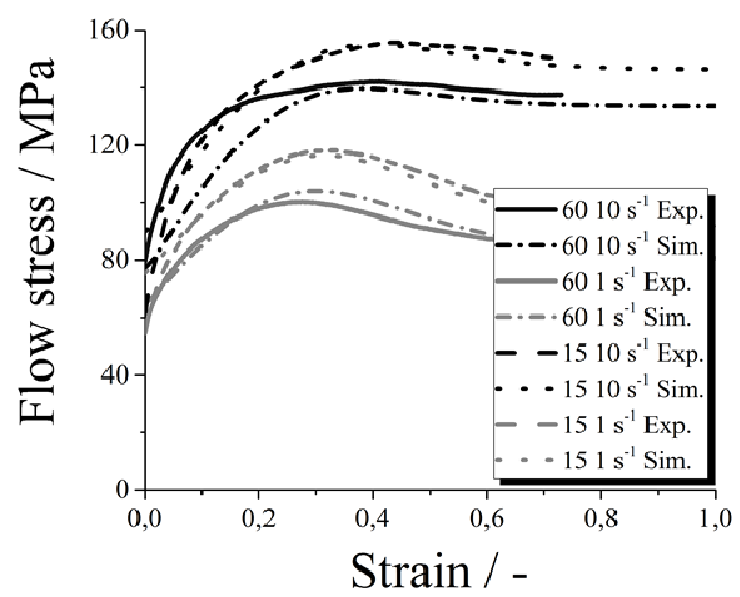

a)

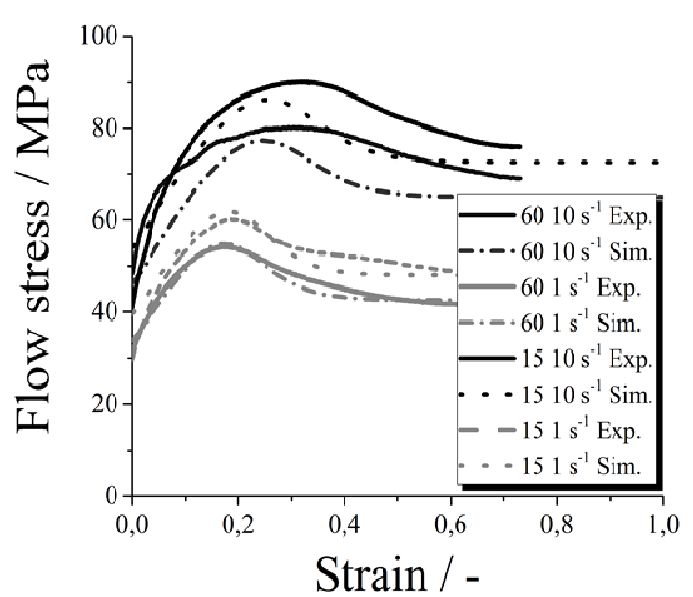

b)

Fig. 1: Comparison of experimental and simulated flow stress at a) $1000{ }^{\circ} \mathrm{C}$ and b) $1200{ }^{\circ} \mathrm{C}$ for $\mathrm{C} 15$ and $\mathrm{C} 60$ for a strain rate of 1 and $10 \mathrm{~s}^{-1}$.

For the following calculation and the forecast of material behavior during processing and final properties of the $\mathrm{C}$ steel family quenched and tempered $\mathrm{C}$ steel grades, namely $\mathrm{C} 22$ and C60, were taken. These grades can be used for massive forged components as well as for flat products. For the calculations the average composition from $\mathrm{C}, \mathrm{Si}$ and $\mathrm{Mn}$ for $\mathrm{C} 22$ and $\mathrm{C} 60$ according to the standard DIN EN 10083-2 are chosen, see Table 2 [10]. 
Table 2: Chemical composition in wt- $\%$ of C22 and C60 according to the standard [10].

\begin{tabular}{|c|c|c|c|}
\hline Alloy & $\mathrm{C}$ & $\mathrm{Si}$ & $\mathrm{Mn}$ \\
\hline C22 & 0.205 & 0.2 & 0.55 \\
\hline C60 & 0.610 & 0.2 & 0.75 \\
\hline
\end{tabular}

Test Case Fast Moving Press. A wheel hub forged in three steps on a fast moving press (FMP) (app. 60 parts per minute) is considered. Time-, temperature- and strain rates where extracted out of FE-simulation by point tracking procedure. Point $\mathrm{P} 1$ is placed under the surface of the part whereas P2 is near to the surface, see Fig. 2. For the first calculation the average temperature and strain rates during deformation are taken in each deformation step. Point P3 differs from point P2 only with regard to the last forming step were a temperature drop from $1120{ }^{\circ} \mathrm{C}$ to $1050{ }^{\circ} \mathrm{C}$ was considered. The average strain rate was app. $20 / \mathrm{s}$ and contact time was 0.06 seconds. Fig. $3 \mathrm{~b}$ ) depicts the austenite grain size (AGS) and temperature evolution for $\mathrm{C} 22$ and $\mathrm{C} 60$ for three different points. The parameters for the input files of the simulation are depicted in Table 3.

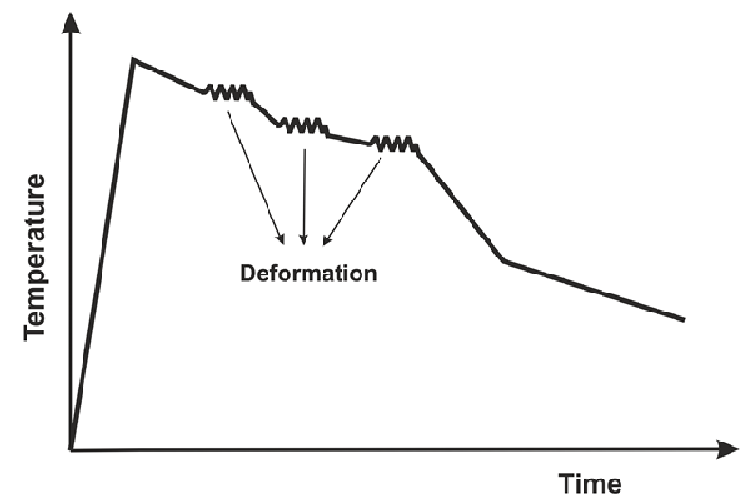

a)

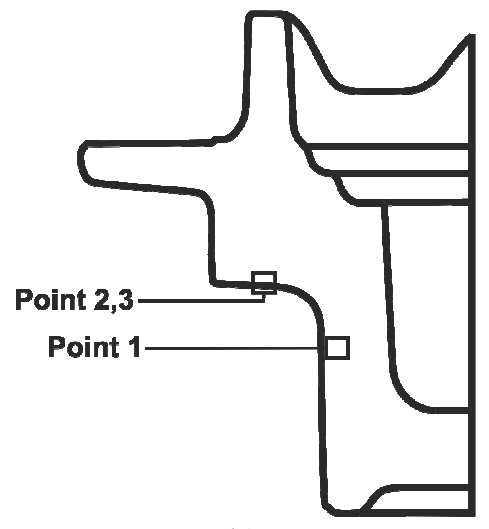

b)

Fig. 2: Schematic depiction of the forging cycle a) and the position of the points in the forged part.

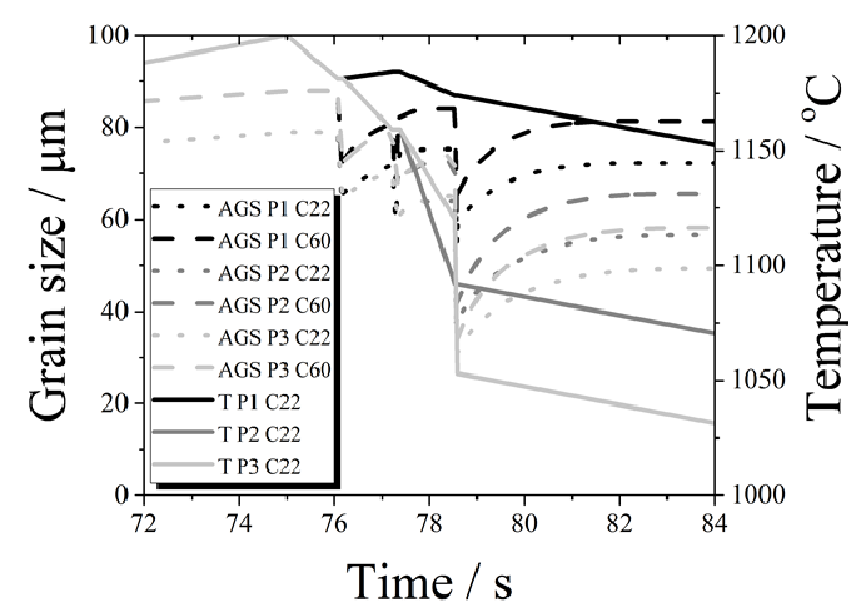

a)

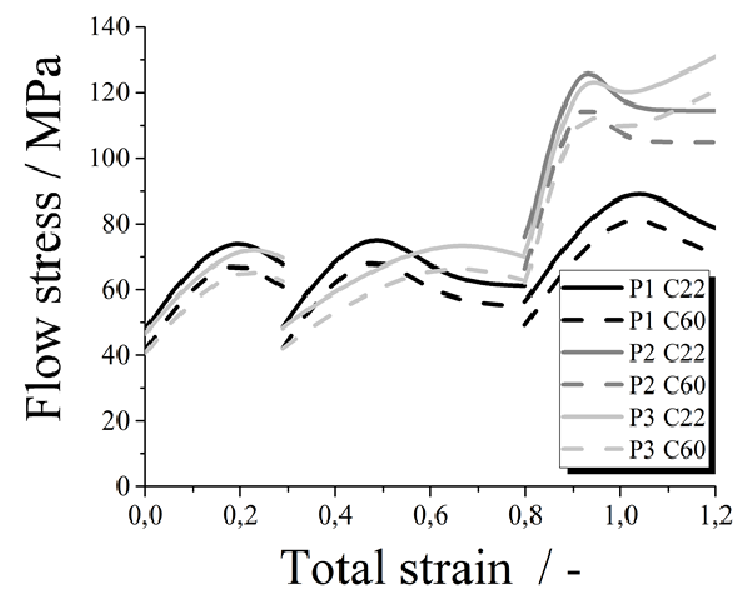

b)

Fig. 3: Austenite grain size (AGS) and temperature evolution for $\mathrm{C} 22$ and $\mathrm{C} 60$ for three different points in a wheel hub for a fast moving press a), and flow stress over total strain b).

After the last forming step, a linear cooling rate of $4{ }^{\circ} \mathrm{C} / \mathrm{s}$ down to $900{ }^{\circ} \mathrm{C}$ and a cooling rate of $1.6^{\circ} \mathrm{C} / \mathrm{s}$ down to $550{ }^{\circ} \mathrm{C}$ were chosen to simulate the transformation behavior and final strength of a forged part. For point P1 the resulting ferrite / perlite content and the yield strength (YS) and tensile 
strength (TS) are listed in Table 5 with the results from the hot rolling mill (HRM), see below. To validate the calculated final properties they are compared with the minimum YS and TS which are recommended by the standard DIN EN 10083-2 [10]. The predicted final properties for the test case of fast moving press were compared to the values witch are specified in the standard DIN EN 10083-2 for part dimensions $<100 \mathrm{~mm}$, see Table 5 .

Table 3: Definition of the simulation steps for the test case fast moving press.

\begin{tabular}{|c|c|c|c|c|c|c|c|c|c|c|}
\hline Point & Simulation Steps & 1 Step & 2 Step & 3 Step & 4 Step & 5 Step & 6 Step & 7 Step & 8 Step & 9 Step \\
\hline \multirow{3}{*}{ P1 } & Temperature $/{ }^{\circ} \mathrm{C}$ & $900-1200$ & $1200-1181$ & $1181-1181$ & $1181-1176$ & 1176-1176 & 1176-1144 & $1144-1144$ & $1144-900$ & $900-550$ \\
\hline & Time / s & 75 & 1.076 & 0.12 & 1.02 & 0.176 & 1.141 & 0.058 & 61 & 211 \\
\hline & Strain rate $/ \mathrm{s}^{-1}$ & 0.0 & 0.0 & 2.5 & 0.0 & 3.8 & 0.0 & 2.7 & 0.0 & 0.0 \\
\hline \multirow{3}{*}{$\mathrm{P} 2$} & Temperature $/{ }^{\circ} \mathrm{C}$ & $900-1200$ & $1200-1181$ & $1181-1181$ & 1181-1159 & 1159-1159 & 1159-1092 & $1092-1092$ & $1092-900$ & $900-550$ \\
\hline & Time / s & 75 & 1.076 & 0.12 & 1.02 & 0.176 & 1.141 & 0.058 & 48 & 211 \\
\hline & Strain rate $/ \mathrm{s}^{-1}$ & 0.0 & 0.0 & 2.0 & 0.0 & 1.4 & 0.0 & 18.4 & 0.0 & 0.0 \\
\hline \multirow{3}{*}{ P3 } & Temperature $/{ }^{\circ} \mathrm{C}$ & $900-1200$ & $1200-1181$ & $1181-1181$ & 1181-1159 & 1159-1159 & 1159-1120 & $1120-1053$ & $1053-900$ & $900-550$ \\
\hline & Time / s & 75 & 1.076 & 0.12 & 1.02 & 0.176 & 1.141 & 0.058 & 38.25 & 211 \\
\hline & Strain rate $/ \mathrm{s}^{-1}$ & 0.0 & 0.0 & 2.0 & 0.0 & 1.4 & 0.0 & 18.4 & 0.0 & 0.0 \\
\hline
\end{tabular}

Test Case Hot Rolling Mill. For the simulation of seven stands in a hot rolling mill the strain rate and strain data for each stand given in [15] were used. Because C-steels are delivered in the normalized rolling condition all rolling stand temperatures are shifted $100{ }^{\circ} \mathrm{C}$ to higher temperatures so that the end rolling temperature was $972{ }^{\circ} \mathrm{C}$, see Table 4 . For simplicity a heating rate was $11^{\circ} \mathrm{C} / \mathrm{s}$ and a holding time of 60 seconds at a reheating temperature of $1250{ }^{\circ} \mathrm{C}$ were assumed. After rolling a linear cooling rate of $10^{\circ} \mathrm{C} / \mathrm{s}$ was taken. In Fig. $4 \mathrm{a}$ ) and b) the grain size evolution and flow stress prediction for $\mathrm{C} 22$ and $\mathrm{C} 60$ in the hot rolling mill are depicted. For the comparison of the final properties predicted by the model and in the standard specified values, see Table 5.

Table 4: Definition of the simulation steps for the stands and interpass times of hot rolling mill.

\begin{tabular}{|c|c|c|c|c|c|c|c|}
\hline Simulation Steps & 1 Step & 2 Step & 3 Step & 4 Step & 5 Step & 6 Step & 7 Step \\
\hline Temperature $/{ }^{\circ} \mathrm{C}$ & $1087-1087$ & $1087-1051$ & $1051-1051$ & $1051-1015$ & $1015-1015$ & $1015-1007$ & $1007-1007$ \\
\hline Time $/ \mathrm{s}$ & 0.0581 & 3.48 & 0.0242 & 2.14 & 0.0116 & 1.48 & 0.0064 \\
\hline Strain rate $/ \mathrm{s}^{-1}$ & 12.9 & 0.0 & 25.2 & 0.0 & 41.3 & 0.0 & 72.7 \\
\hline Simulation Steps & 8 Step & 9 Step & 10 Step & 11 Step & 12 Step & 13 Step & 14 Step \\
\hline Temperature $/{ }^{\circ} \mathrm{C}$ & $1007-996$ & $996-996$ & $996-984$ & $984-984$ & $984-972$ & $972-972$ & $972-550$ \\
\hline Time $/ \mathrm{s}$ & 1.01 & 0.0036 & 0.79 & 0.0023 & 0.63 & 0.0016 & 42.2 \\
\hline Strain rate $/ \mathrm{s}^{-1}$ & 0.0 & 94.2 & 0.0 & 115.0 & 0.0 & 131.0 & 0.0 \\
\hline
\end{tabular}

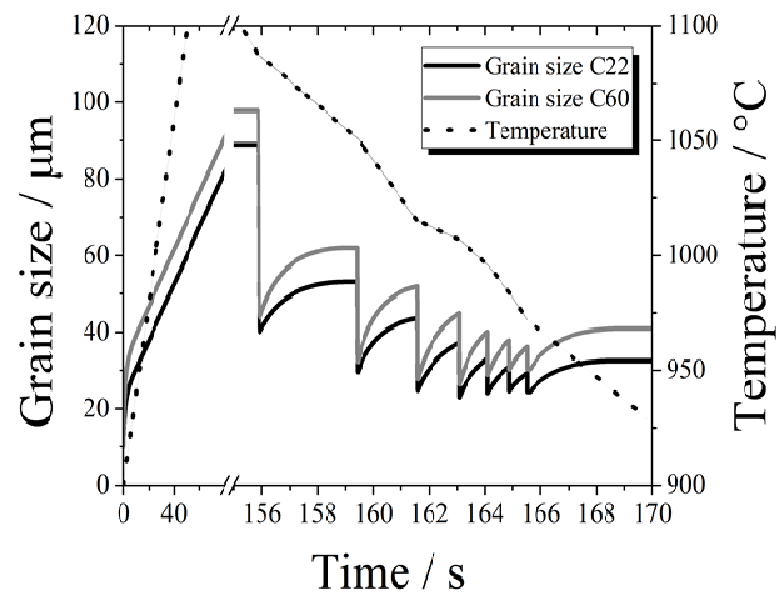

a)

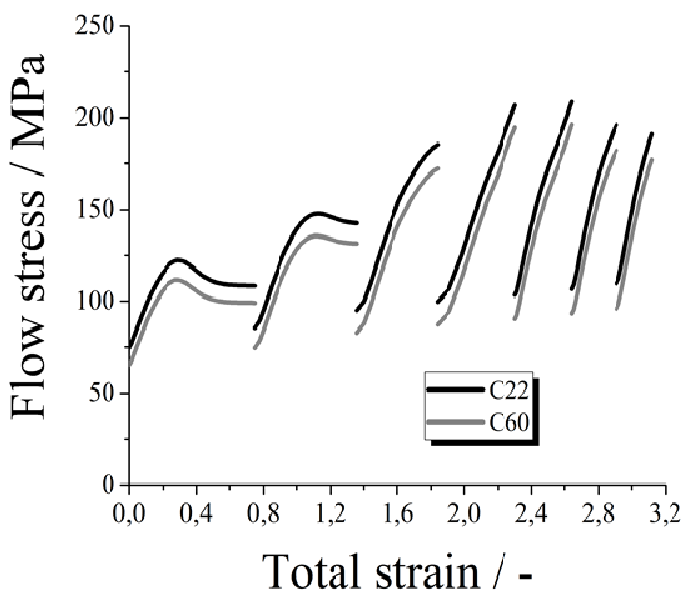

b)

Fig. 4: Calculated grain size evolution, a) and flow stress, b) for C22 and C60 in a hot rolling mill. 
Table 5: Comparison of calculated versus in DIN EN 10083-2 specified minimum values for yield strength (YS) and tensile strength (TS) for C22 and C60 for small $(<16 \mathrm{~mm})$ and large $(<100 \mathrm{~mm})$ dimensions. In addition, calculated ferrite/pearlite fractions $(\mathrm{F} / \mathrm{P})$ are given for all simulation cases.

\begin{tabular}{|c|c|c|c|c|c|c|c|c|}
\hline \multirow{2}{*}{ Alloy } & \multicolumn{2}{|c|}{$\begin{array}{c}\text { YS / TS in MPa for small } \\
\text { dimensions and HRM } \\
\text { model results }\end{array}$} & $\begin{array}{c}\text { Difference } \\
\text { in } \%\end{array}$ & $\begin{array}{c}\text { F/P in } \% \\
\text { HRM model } \\
\text { results }\end{array}$ & \multicolumn{2}{|c|}{$\begin{array}{c}\text { YS / TS in MPa for large } \\
\text { dimensions and HRM } \\
\text { model results }\end{array}$} & $\begin{array}{c}\text { Difference } \\
\text { in } \%\end{array}$ & $\begin{array}{c}\text { F / P in \% } \\
\text { FMP model } \\
\text { results }\end{array}$ \\
\cline { 2 - 9 } & DIN EN 10083 & Model & YS / TS & Model & DIN EN 10083 & Model & YS / TS & Model \\
\hline C22 & $240 / 430$ & $269 / 466$ & $11 / 8$ & $62 / 38$ & $210 / 410$ & $204 / 393$ & $3 / 4$ & $76 / 24$ \\
\hline C60 & $380 / 710$ & $395 / 754$ & $4 / 6$ & $2 / 98$ & $340 / 670$ & $317 / 628$ & $7 / 6$ & $10 / 90$ \\
\hline
\end{tabular}

In Fig. 5, minimum recommended yield strength (YS) (a) and minimum tensile strength (TS) (b) according to standard DIN EN 10083-2 are compared with the model results.

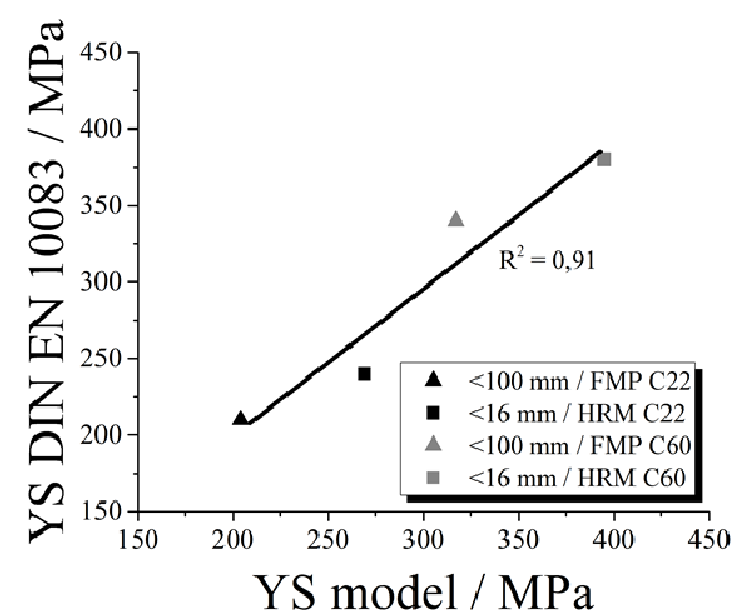

a)

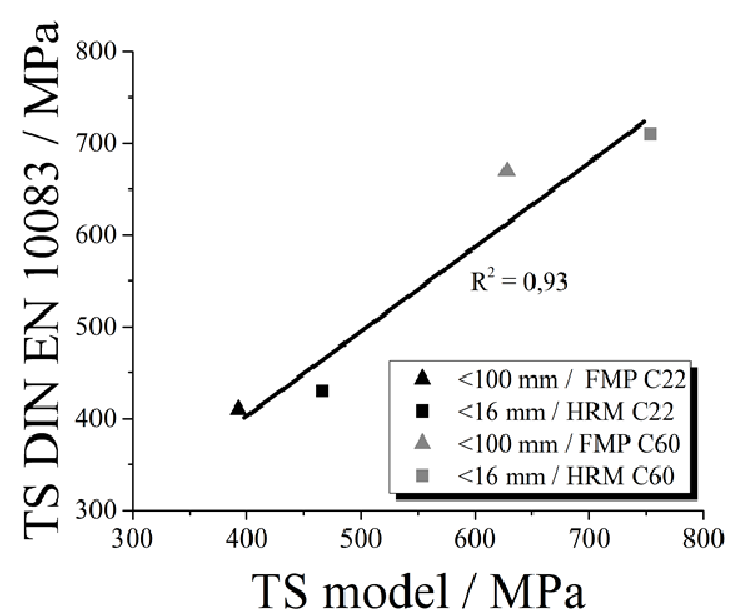

b)

Fig. 5: Minimum YS according to standard DIN EN 10083-2 (YS DIN EN 10083), a) and minimum TS according to standard DIN EN 10083-2 (TS DIN EN 10083), b) specified for C22 and C60 for the dimensions $<16 \mathrm{~mm}$ and $<100 \mathrm{~mm}$ as well as the model results, each compared with model results.

\section{Discussion}

The test case of the fast moving press was performed to see whether the model would be stable after an implementation into an FE-software under multi step forging operations with different input grain sizes and strong temperature as well as strain rate gradients during deformation. During an FEsimulation also higher strain rates and strains can occur than those for which the model was adjusted to. Therefore the model was also tested by extrapolation to strain rates up to $100 \mathrm{~s}^{-1}$ and strains up to 5 , not shown.

As test cases for the validation a fast moving press and a hot rolling mill were selected, because they differ in the process window regarding temperature and strain rate. Both test cases show that the model has the following features: It is able to predict the grain size and flow stress in a wide range of temperature, strain rate and strain regime. Even though no own experimental data is available, the predicted grain size, flow stress and amount of phases as well as the final properties are in accordance with the results in literature and standards documented by other authors. For the test case of the fast moving press even less information for comparison is available than for the test case hot rolling mill. Grain size predictions for hot rolling mills range between $100-10 \mu \mathrm{m}$ depending on steel grade and exact processing window, example is given in [16]. 
Jaipal at al. investigated the flow stress of C15 and C60 also for higher strain rates [17]. For strain rate $70 \mathrm{~s}^{-1}$ for $\mathrm{C} 15$ they measured a steady state stress of $240 \mathrm{MPa}$ whereas the current model is predicting $265 \mathrm{MPa}$ and that is satisfactorily taking into account the uncertainties.

Regarding the prediction of material behavior and final properties of the $\mathrm{C}$ steel family. The authors do not believe that the description of the shear modulus and diffusivity reflects precisely the properties of the material. Nonetheless, it gives the adjusted model the capability to account for the effect of different composition and by that gives the model the capability to predict the effect of varying composition within the $\mathrm{C}$ steel family correctly.

There are some studies in literature suggesting that carbon has no significant influence on flow stress while other found that carbon increase the flow stress. However if plain carbon steels without any micro alloying elements or other carbide forming elements like $\mathrm{Cr}$ are considered, a decrease in flow stress due to carbon has been found [8]. This is in accordance to a study of Jaipal at al. [17].

It has to be stated that in so-called physically based models usually the alloying dependency of the model constants is not very well known. Nevertheless it should be aimed during modelling to account for the effect of the major alloying elements in one family to give the models a higher validity. That was targeted by the description of alloying dependent diffusivity, mobility and shear modulus. It is important to note that the reduction of shear modulus with increasing carbon content reflects the observation that the flow stress is decreasing as well.

However, for other alloying elements this description might be misleading. According to Frost and Ashby the activation energy or obstacle energy which restricts the thermally activated motion of dislocations can be divided into strong, medium and weak obstacles [18]. All three kinds of obstacles show strength proportional to the product of $\mathrm{G}^{*} \mathrm{~b}^{3}$ (G: shear modulus, b: Burger's vector). This implies that all alloying elements which decrease the shear modulus should decrease the flow stress as well. In fact nearly all alloying elements decrease the shear modus but most are known to increase the flow stress during hot forming (e.g. silicon). However in the case of carbon the description of shear modulus also reflects that the strength of obstacles is changed due to the carbon dependent description of shear modulus and this is well in line with the expectations since higher carbon content leads to higher diffusivity, creep and lower flow stress. A better description of the obstacle energy in dependence of the alloying elements would be helpful to establish more generalized and physically based process models.

\section{Conclusions}

In this paper the results of a physically-based one-parameter model are presented being capable to predict the material behavior during complete process cycles for different $\mathrm{C}$-steels and processing routes. At the current status the model accounts for grain growth, static and dynamic recrystallization, transformation and the final properties at the end of the process cycle. Flow stress as well as the strength are described by using a single dislocation density.

The results of the model are plausible and the description of diffusivity, mobility, basic strength and shear modulus as a function of carbon content offers a predictive capability. This holds also for the use of a fitting function for the equilibrium ferrite fraction and other quantities like the melting temperature from ThermoCalc.

\section{References}

[1] Y. C. Lin, X. Chen, A critical review of experimental results and constitutive description for metals and alloys in hot working, Materials and Design 32, 1733-1759, 2011.

[2] R. Liang, A.S. Khan, A critical review of experimental results and constitutive models for BBC and FCC metals over a wired range of strain rates and temperatures, International Journal of Plasticity 15, 963-980, 1999.

[3] M. Goerdeler, G. Gottstein, A microstructural work hardening model based on three internal state variables. Materials Science and Engineering A309-310, 377-381, 2001. 
[4] G.V.S.S. Prasad, M. Goerdeler, G. Gottstein, Work hardening model based on multiple dislocation densities, Materials Science and Engineering A400-401, 231-233, 2005.

[5] U.F. Kocks, Laws for work-hardening and low-temperature creep, J. Eng. Mater. Technol. 98, 76-85, 1976.

[6] F. Roters, D. Raabe, G. Gottstein, Work hardening in heterogeneous alloys - A microstructural approach based on three internal state variables, Acta Materialia 48, 4181-4189, 2000.

[7] Autoren: Werkstoff- und Prozessentwicklung von mikrolegierten AFP-Stählen mittels gekoppelter Thermodynamik und Mikrostrukturmodellierung, Abschlussbericht zum IGF-Vorhaben 17246 N / 1, http://www.fsv-hagen.de/images/ergebnisse/p_b_imu.pdf.

[8] K. Schacht, A. Simushkin, U. Prahl, W. Bleck, Influence of model parameters on the flow stress prediction using rate laws for dislocation density and dynamic recrystallization, Forming Technology Forum, 2014.

[9] DIN EN 10084: Einsatzstähle - Technische Lieferbedingungen.

[10]DIN EN 10083-2: Vergütungsstähle - Technische Lieferbedingungen für unlegierte Stähle.

[11]D.R. Lesuer, C.K. Syn, J.D.Whittenberger, M. Carsi, O.A. Ruano, O.D. Sherby, Creep behavior of $\mathrm{Fe}-\mathrm{C}$ alloys at high temperatures and high strain rates, Materials Science and Engineering A317, $101-107,2001$.

[12]T. Sakai, M. Ohashi, The effect of T, strain rate and carbon content on hot deformation of carbon steels, J. Iron Steel Institute, Japan, 67, 1981, 134-143.

[13]T. Gladman, The Physical Metallurgy of Microalloyed Steels, Medium and high carbon steels, The University press, Cambridge, 1997, 336-341.

[14]J. Majta, M. Cola, P. Hochanadel, A.K. Zurek, P. Hochanadel, M. Pietrzyk, An integrated computer model with applications for austenite-to-ferrite-transformations during hot deformation of NB-microalloyed steels, Metallurgical and Materials Transactions A, 33A, 1509-1520, 2002.

[15]F. Siciliano, J.Jr. Jonals, J.J. Jonals, Mathematical Modeling of the Hot Strip Rolling of Microalloyed Nb, Multiply-Alloyed Cr-Mo, and Plain C-Mn Steels, Metallurgical and Materials 'Transactions A, 31, 511-530, 2000.

[16]C.M. Sellars and J.A.Whiteman, Recrystallisation and grain growths in hot rolling, Metal Science, 187-194, 1979.

[17]J. Jaipal, C.H.J. Davies, B.P. Wynne, D.C. Collinson, A. Brownrigg, P.D. Hodgson, Effect of carbon content on the hot flow stress and dynamic recrystallisation behaviour of plain carbon steels, THERMEC'97, Vol. 1, The Minerals, Metals and Materials Society, 539-545, 1997.

[18]H.J. Frost, M.F. Ashby, Deformation Mechanism Maps, Pergamon Press, Oxford, 1982. 